\title{
Datos de base de Andarax y Campo de Tabernas
}

La zona del Andarax y el Campo de Tabernas comprende treinta y siete términos municipales de la provincia de Almeria. Veinticuatro de estos municipios se integran completamente en la zona estudiada: Abla, AlboIoduy, Alhabia, Alsodux, Benahadux, Benizalón, Castro de Filabres, Gádor, Gérgal, Huércal de Almería, Nacimiento, Olula de Castro, Pechina, Rioja, Santa Cruz, Santa Fé de Mondújar, Senés, Tabernas, Tahal, Las Tres Villas, Turrillas, Uleila del Campo, Velefique y Viator'.

Hay otros trece municipios integrados solo parcialmente: Abrucena, Alhama de Almería, Alicún, Almería, Bédar, Bentarique, Fiñana, Huécija, Lubrín, Lucainena de las Torres, Sorbas, Terque y Turre.

En esta zona se han localizado un total de 554 inmuebles, de los cuales el 63\% corresponden al patrimonio arqueológico, el 26\% al patrimonio arquitectónico y el $11 \%$ al patrimonio etnológico.

El motivo de que el número de inmuebles mas alto sea el correspondiente al patrimonio arqueológico puede deberse por una parte, a que este se localiza casi exclusivamente mediante coordenadas, y por otra parte a que en Andalucía oriental la presencia humana en la Prehistoria reciente es muy fuerte, ya que desde el Neolitico comienzan a establecerse asentamientos utilizando sobre todo las cuencas de los ríos Andarax y Nacimiento con el consiguiente aprovechamiento del agua para la agricultura. Asi tenemos grandes poblados, algunos fortificados como Los Millares, que es más importante de la zona, Las Juntas en Abla, La Umbría en Gérgal o Los Álamos en el Campo de Tabernas.

Junto a estas poblaciones se encuentran gran número de construcciones megaliticas como Los Milanes en Abla, o la Necrópolis Megalítica de Gádor.
También abundan los sitios con manifestaciones rupestres que se localizan sobre todo en los municipios de Gérgal y Nacimiento.

En cuanto al patrimonio arquitectónico la mayor parte de los registros que están localizados en el mapa corresponden a los inmuebles protegidos, sobre todo los que se encuentran dentro del Centro Histórico de Almeria; inmuebles pertenecientes al Registro Andaluz de Arquitectura Contemporánea (RAAC); inmuebles procedentes del Inventario de Cortijos, Haciendas y Lagares, asi como la arquitectura defensiva.

El patrimonio etnológico se encuentra representado en su mayor parte por los cortijos dedicados tradicionalmente al cultivo y transformación de la uva, aunque actualmente casi todos han perdido esa función y se dedican al cultivo de frutales, cereales y otras actividades agropecuarias. Junto a estos se registran también lagares y bodegas, asi como otros inmuebles relacionados con el aprovechamiento del agua como norias, aljibes, boqueras, etc.

Desde el punto de vista de las tipologías funcionales y los periodos históricos a los que se asocia el patrimonio inmueble de la zona estudiada, se han utilizado los términos del Tesauro de Patrimonio Histórico Andaluz agrupándolos de la siguiente manera:

-Edificaciones productivas: los inmuebles pertenecientes a esta tipología suponen un $17 \%$ del total.

-Edificaciones dotacionales, que agrupa distintas tipologías como las construcciones funerarias, sanitarias, de espectáculo, etc. Los inmuebles pertenecientes a esta tipologia suponen un $38 \%$ del total.
- Asentamientos y espacios libres: los inmuebles pertenecientes a esta tipología suponen un $23 \%$ del total.

- Edificaciones militares: los inmuebles pertenecientes a esta tipología suponen un $9 \%$ del total.

- Edificaciones religiosas: los inmuebles pertenecientes a esta tipología suponen un 5\% del total.

- Edificaciones residenciales: los inmuebles pertenecientes a esta tipología suponen un $5 \%$ del total.

- Sitios con representaciones rupestres: los inmuebles pertenecientes a esta tipología suponen un 3\% del total.

Entre los periodos históricos destaca la Prehistoria reciente con 269 inmuebles; le sigue la Edad Media con 110 inmuebles, casi todos pertenecientes a la arquitectura defensiva; después están los inmuebles de la Edad Contemporánea, entre los que se encuentran los pertenecientes al RAAC y al Inventario de Cortijos, Haciendas y Lagares; de Época Romana se cuentan 76 inmuebles, de los que la mayoría son asentamientos y villae; de la Protohistoria, 19; y de la Edad Moderna 28.

Pilar Mondéjar Fernández de Quincoces Salud Soro Cañas

Centro de Documentación y Estudios del Instituto Andaluz del Patrimonio Histórico

\section{Notas}

' La información de carácter patrimonial contenida en el Sistema de Información para la Gestión Integral del Patrimonio Cultural relativa a la zona de Andarax y el campo de Tabernas se analiza en base al patrimonio inmueble que se haya localizado cartográficamente en la misma.



Conjunto Monumental de la Alcazaba de Almería Foto: Juan Carlos Cazalla, IAPH

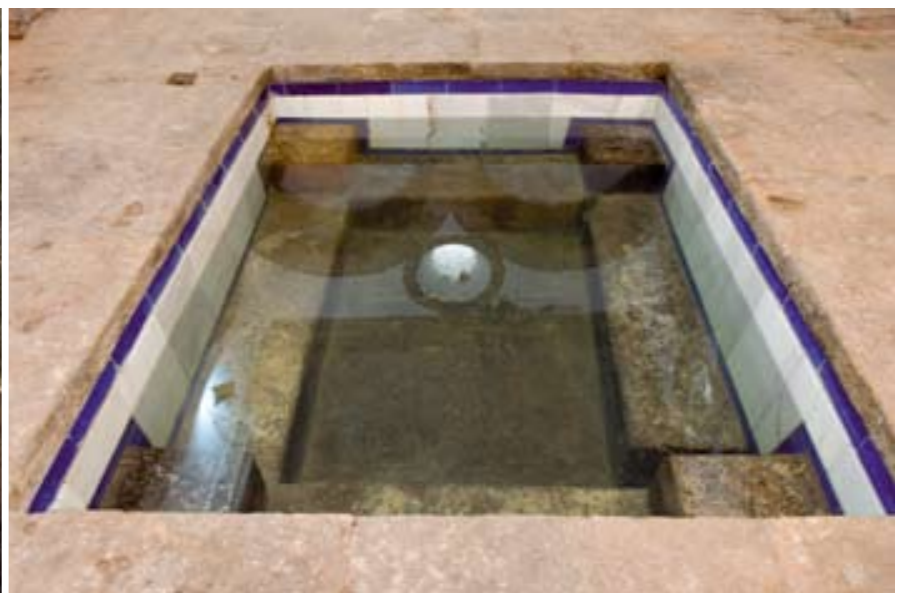

Instalaciones del balneario de Sierra Alhamilla.

Foto: Juan Carlos Cazalla, IAPH 

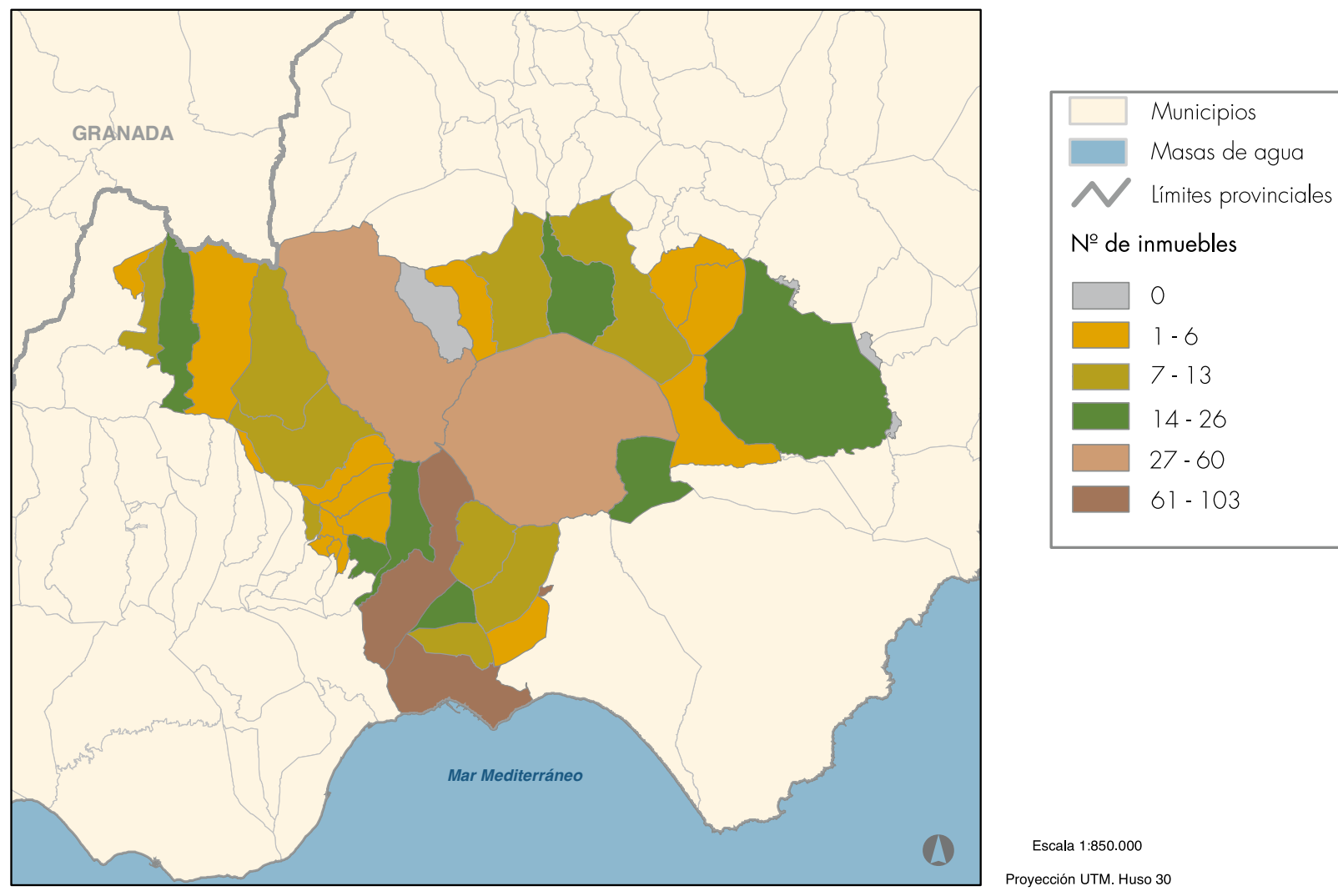

№ de inmuebles

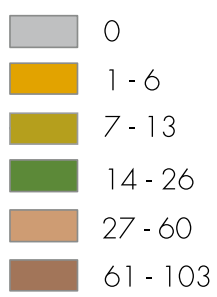

Escala 1:850.000

Proyección UTM. Huso 30

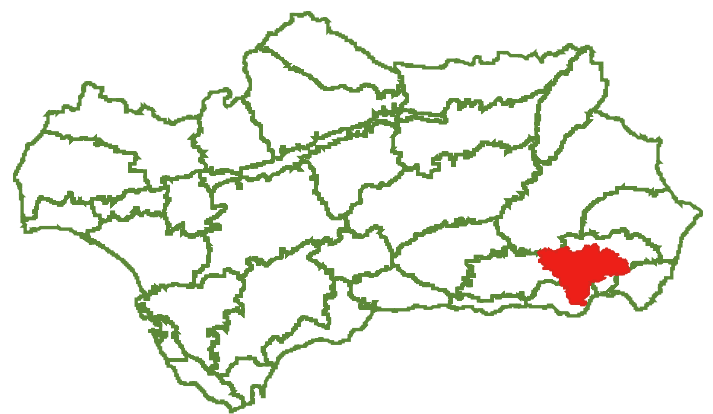

Gráfico 1. Localización del área

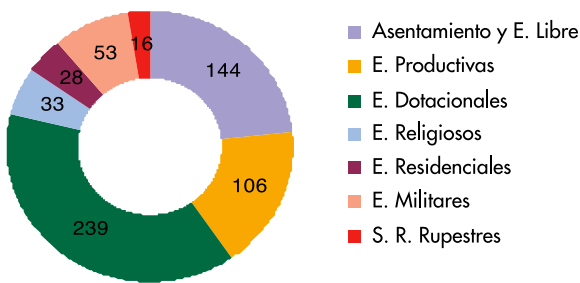

Gráfico 3. Tipologías funcionales

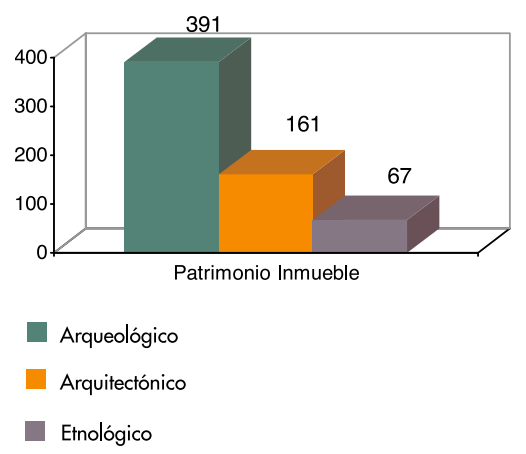

Gráfico 2. Distribución por tipo

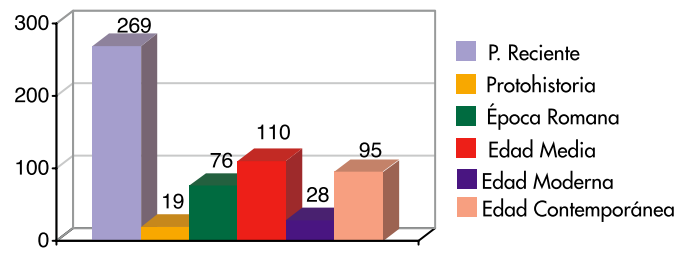

№ inmuebles

Gráfico 4. Periodos históricos 